\title{
Biofilm Formation among Clinical and Food Isolates of Listeria monocytogenes
}

\author{
Joana Barbosa, Sandra Borges, Ruth Camilo, Rui Magalhães, Vânia Ferreira, Isabel Santos, \\ Joana Silva, Gonçalo Almeida, and Paula Teixeira
}

Centro de Biotecnologia e Química Fina (CBQF), Laboratório Associado, Escola Superior de Biotecnologia, Universidade Católica Portuguesa/Porto, Rua Dr. António Bernardino Almeida, 4200-072 Porto, Portugal

Correspondence should be addressed to Paula Teixeira; pcteixeira@porto.ucp.pt

Received 16 July 2013; Accepted 7 October 2013

Academic Editor: José M. Pérez-Donoso

Copyright (C) 2013 Joana Barbosa et al. This is an open access article distributed under the Creative Commons Attribution License, which permits unrestricted use, distribution, and reproduction in any medium, provided the original work is properly cited.

Objective. A total of 725 Listeria monocytogenes isolates, 607 from various foods and 118 from clinical cases of listeriosis, were investigated concerning their ability to form biofilms, at $4^{\circ} \mathrm{C}$ during 5 days and at $37^{\circ} \mathrm{C}$ during $24 \mathrm{~h}$. Methods. Biofilm production was carried out on polystyrene tissue culture plates. Five L. monocytogenes isolates were tested for biofilm formation after being exposed to acidic and osmotic stress conditions. Results. Significant differences $(P<0.01)$ between clinical and food isolates were observed. At $37^{\circ} \mathrm{C}$ for $24 \mathrm{~h}$, most food isolates were classified as weak or moderate biofilm formers whereas all the clinical isolates were biofilm producers, although the majority were weak. At $4^{\circ} \mathrm{C}$ during 5 days, 65 and $59 \%$ isolates, from food and clinical cases, respectively, were classified as weak. After both sublethal stresses, at $37^{\circ} \mathrm{C}$ just one of the five isolates tested was shown to be more sensitive to subsequent acidic exposure. However, at $4^{\circ} \mathrm{C}$ both stresses did not confer either sensitivity or resistance. Conclusions. Significant differences between isolates origin, temperature, and sublethal acidic stress were observed concerning the ability to form biofilms. Strain, origin, and environmental conditions can determine the level of biofilm production by L. monocytogenes isolates.

\section{Introduction}

Listeria monocytogenes has been responsible for several outbreaks of foodborne diseases, worldwide. Listeriosis is largely confined to its risk groups of pregnant women, the elderly and immunocompromised individuals with high morbidity and mortality rates [1]. According to the European Food Safety Authority this bacterium remains a concern; the number of listeriosis cases in humans increased by $19.1 \%$ compared to 2008, with 1,645 confirmed cases recorded in 2009 [2].

L. monocytogenes can colonize most of the surfaces and equipment encountered in the food industry including refrigerated environments, and persistent strains have been reported [3-5]. During processing this organism can easily contaminate the final food product. Many bacteria are able to attach and colonize environmental surfaces by producing biofilms, a three-dimensional matrix of extracellular polymeric substances (EPS) [6]. Biofilms produced by $L$. monocytogenes are structurally simple in comparison to those by other organisms, and a mature biofilm community can be established after $24 \mathrm{~h}[6,7]$. Once established and in comparison with planktonic cells, biofilms have greater resistance to antimicrobial agents, to U.V. light, to desiccation, and to treatments with sanitizing agents $[8,9]$. L. monocytogenes has been reported as capable of attaching and developing biofilms on a variety of surfaces, for example, stainless steel, polymers, and rubber gaskets $[6,8,10]$. This capacity varies depending on several factors: the strains considered $[8,11,12]$, the topology of surface [13-15], the growth phase [9], the temperature [9], the growth media [16], and the presence of other microorganisms [17].

Djordjevic et al. [18] reported that apparently there is a relationship between phylogeny and the ability to produce biofilms. Environmental stress such as starvation also influences both attachment and biofilm development in $L$. monocytogenes $[19,20]$; generally the ability to produce biofilms is enhanced after environmental stress exposure. It is therefore crucial to study the factors that contribute to production/variation in biofilm formation by L. monocytogenes strains in order to optimize preventative measures 
and thereby minimize the risk that biofilm production by $L$. monocytogenes presents to food industries.

The aim of this study was to characterize $725 \mathrm{~L}$. monocytogenes isolates, 607 from various food products and 118 clinical isolates, with respect to their ability to form biofilms in 96 wells microtiter plates, at $4^{\circ} \mathrm{C}$ during 5 days and at $37^{\circ} \mathrm{C}$ during $24 \mathrm{~h}$. The behavior of five food L. monocytogenes isolates on their ability to produce biofilms, after exposure to acidic and osmotic sublethal stresses, was also investigated.

\section{Material and Methods}

2.1. Origin of Isolates. A total of 725 L. monocytogenes isolates were studied; 607 recovered from foods by quality control Portuguese laboratories (23\% serogroup IIa, 23\% serogroup IIb, 9\% serogroup IIc, and $85 \%$ serogroup IVb) and 118 isolates (12\% serogroup IIa, 21\% serogroup IIb, and $85 \%$ serogroup IVb) obtained from clinical cases of listeriosis that occurred in Portugal and collected from major Portuguese hospitals, between 2003 and 2008. These isolates were deposited and stored at $-80^{\circ} \mathrm{C}$ in Tryptone Soya Broth supplemented with $0.6 \%(\mathrm{w} / \mathrm{v})$ of yeast extract (TSBYE, Pronadisa, Madrid, Spain) containing 30\% (v/v) glycerol in the Listeria culture collection of CBQF-Escola Superior de Biotecnologia (Porto, Portugal) and used in the current investigation.

2.2. Growth and Storage Conditions. Working cultures were inoculated from frozen stocks onto Tryptone Soya Agar containing $0.6 \%(\mathrm{w} / \mathrm{w})$ of yeast extract (TSAYE; Pronadisa) and incubated at $37^{\circ} \mathrm{C}$ during $24 \mathrm{~h}$.

Each strain was subcultured overnight in TSBYE and was further inoculated $(10 \% \mathrm{v} / \mathrm{v})$ into $10 \mathrm{~mL}$ of TSBYE and incubated at $37^{\circ} \mathrm{C}$ for 18 to $20 \mathrm{~h}$. This procedure was repeated twice.

2.3. Biofilm Production. Biofilm production was carried out as previously described by Cerca et al. [21]. Although polystyrene is infrequently present in food production or clinical settings, it was used for practical reasons due to the high number of isolates being investigated. Each well of (Brand, Wertheim, Germany) was filled with $180 \mu \mathrm{L}$ of TSBYE and $20 \mu \mathrm{L}$ of an overnight culture obtained as described above. The plates were covered and incubated aerobically at $37^{\circ} \mathrm{C}$ during $24 \mathrm{~h}$ and at $4^{\circ} \mathrm{C}$ during 5 days. The biofilms were visualized with a $2 \%$ crystal violet solution and quantified by measuring the optical density (OD) at $655 \mathrm{~nm}$ using a plate reader (Microplate reader, Bio-Rad, Hercules, CA, USA). For classification of isolates according to their ability to form biofilms, a cut-off value was obtained. The cut-off value (ODc) for determining a biofilm producer and the classification of the isolates as nonbiofilm producers (OD $\leq \mathrm{ODc}$ ), weak biofilm producers (ODc $<\mathrm{OD} \leq 2 \times \mathrm{ODc}$ ), moderate biofilm producers $(2 \times \mathrm{ODc}<\mathrm{OD} \leq 4 \times \mathrm{ODc})$, and strong biofilm producers $(4 \times \mathrm{ODc}>\mathrm{OD})$. Therefore, the isolates were classified as nonbiofilm producers, weak, moderate, or strong biofilm producers for each assay [14]. For each strain, all the experiments were performed at least six times: three wells in two different polystyrene tissue culture plates. The wells with medium and without inoculating the bacteria were used as negative controls.

\subsection{Biofilm Formation after Exposure to Acidic and Osmotic Stresses}

2.4.1. Isolates and Growth. Five isolates were chosen from different plants: 1079 (serotype 1/2b-3b), 1055/4 (serotype 4b$4 d-4 e$ ), 1509/2 (serotype $1 / 2 c-3 c$ ), 1592/2 (serotype $1 / 2 b-3 b$ ), and 1743 (serotype $4 \mathrm{~b}-4 \mathrm{~d}-4 \mathrm{e}$, resident strain). Since these dairy isolates are commonly in contact with a wide range of environmental stresses, such as high salt concentration, low $\mathrm{pH}$, and $\mathrm{a}_{\mathrm{w}}$, these isolates were selected to study the effect of such stresses on biofilm formation ability.

Cultures were produced as described previously, but only $0.1 \mathrm{~mL}$ of the last inoculum was transferred to $10 \mathrm{~mL}$ of TSBYE $(1: 100)$ and further incubated at $37^{\circ} \mathrm{C}$ for $18-20 \mathrm{~h}$. Each isolate was harvested by centrifugation $(8877 \times \mathrm{g}, 10$ minutes, $4^{\circ} \mathrm{C}$; Rotina 35R, Hettich, Germany), resuspended in $10 \mathrm{~mL}$ of sterile quarter strength Ringer's solution (Lab $\mathrm{M}$, Lancashire, UK) and mixed to obtain an inoculum of approximately $10^{7} \mathrm{CFU} / \mathrm{mL}$, quantified by the drop count technique [22] on TSAYE and further incubated for $24 \mathrm{~h}$ at $37^{\circ} \mathrm{C}$.

2.4.2. Biofilm Assay after Exposure to Sublethal Stresses. The sublethal conditions were previously established [23]. The inoculum prepared as described previously was inoculated $(0.5 \mathrm{~mL})$ into glass flasks containing $49.5 \mathrm{~mL}$ of BPW (Buffered Peptone Water, Lab M).

The $\mathrm{pH}$ and the $\mathrm{NaCl}$ concentration were adjusted accordingly (BPW at pH 3.5 with lactic acid (1 M, José M. Vaz Pereira, Lda, Lisbon, Portugal)) and BPW containing saturated solutions of $30 \%$, only for isolates $1592 / 2$ and 1743 , or $40 \%(\mathrm{w} / \mathrm{v})$ of $\mathrm{NaCl}$ (Panreac, Barcelona, Spain); cells were subjected to stress conditions for $1 \mathrm{~h}$ at $37^{\circ} \mathrm{C}$. Samples were taken at time 0 (time of inoculation) and after 60 minutes. For each sublethal stress, a control was performed (BPW at $\mathrm{pH}=7.0$ and no added salt). The survivors were enumerated, in duplicate by the drop count technique [22] on TSAYE, and further incubated for $24 \mathrm{~h}$ at $37^{\circ} \mathrm{C}$. The results were expressed in $\mathrm{CFU} / \mathrm{mL}$.

After the exposure to these sublethal stresses, each suspension was harvested by centrifugation $(8877 \times \mathrm{g}, 10$ minutes, $4^{\circ} \mathrm{C}$; Rotina $35 \mathrm{R}$ ) and the pellet resuspended with $50 \mathrm{~mL}$ of TSBYE. From this suspension, $20 \mu \mathrm{L}$ were added to three wells of sterile polystyrene tissue culture plates containing $180 \mu \mathrm{L}$ of TSBYE. The plates were covered and incubated aerobically for $24 \mathrm{~h}$ at $37^{\circ} \mathrm{C}$ and 5 days at $4^{\circ} \mathrm{C}$. The quantification of biofilms was done as described above.

2.5. Statistical Analysis. To test significant differences between the two temperatures used and within replicates as well as between food and clinical isolates, the ANOVA test was applied using the software KaleidaGraph 4.0 (Synergy Software Reading, PA, USA). 
TABLE 1: Classification of food and clinical isolates belonging to different serogroups isolates concerning their ability to form biofilm during five days at $4^{\circ} \mathrm{C}$ and 24 hours at $37^{\circ} \mathrm{C}$ (results are expressed as $\%$ of isolates).

\begin{tabular}{|c|c|c|c|c|c|c|c|c|}
\hline Serogroup & NF-C & NF-F & WF-C & WF-F & MF-C & MF-F & SF-C & SF-F \\
\hline & \multicolumn{8}{|c|}{$4^{\circ} \mathrm{C} / 5$ days } \\
\hline IIa & 8 & 16 & 92 & 72 & 0 & 12 & 0 & 0 \\
\hline IIb & 48 & 24 & 52 & 62 & 0 & 14 & 0 & 0 \\
\hline IIc & - & 20 & - & 71 & - & 9 & - & \\
\hline \multirow[t]{2}{*}{$\mathrm{IVb}$} & 44 & 28 & 56 & 63 & 0 & 9 & 0 & 0 \\
\hline & \multicolumn{8}{|c|}{$37^{\circ} \mathrm{C} / 24$ hours } \\
\hline IIa & 0 & 0 & 8 & 50 & 92 & 48 & 0 & 1 \\
\hline $\mathrm{IIb}$ & 0 & 0 & 38 & 57 & 43 & 40 & 19 & 3 \\
\hline IIc & - & 2 & - & 66 & - & 30 & - & 2 \\
\hline $\mathrm{IVb}$ & 0 & 2 & 87 & 81 & 12 & 17 & 1 & 0 \\
\hline
\end{tabular}

NF-C: non formers of clinical origin; NF-F: non formers of food origin; WF-C: weak formers of clinical origin; WF-F: weak formers of food origin; MF-C: moderate formers of clinical origin; MF-F: moderate formers of food origin; SF-C: strong formers of clinical origin; SF-F: strong formers of food origin.

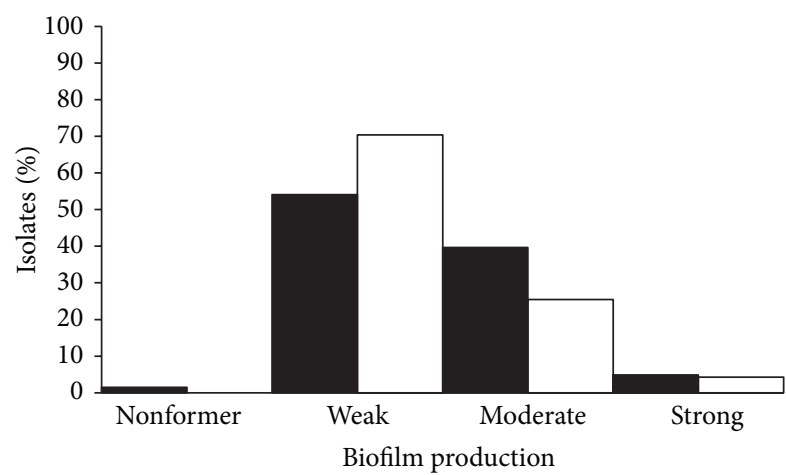

FIGURE 1: Biofilm production by clinical ( $\square$ ) and food ( $\square$ ) isolates of L. monocytogenes at $37^{\circ} \mathrm{C}$ during $24 \mathrm{~h}$.

\section{Results and Discussion}

It is commonly accepted that cells in biofilms are more resistant to biocides, antibiotics, antibodies, and surfactants than are planktonic cells. Therefore, knowledge on biofilm capacity of foodborne pathogens is of major importance for the food industry, in order to define the most effective cleaning and disinfection strategies, and also in clinical settings when establishing the most appropriate therapeutic regimes. Several L. monocytogenes isolates from food and clinical origin were studied concerning their ability to produce biofilms at 4 and $37^{\circ} \mathrm{C}$. Significant differences $(P<0.01)$ between clinical and food isolates were observed in both conditions. At $37^{\circ} \mathrm{C}$ for $24 \mathrm{~h}$, most food isolates were classified as weak ( $n=328 ; 54 \%)$, or moderate biofilm formers $(n=240,40 \%)$. All clinical isolates were biofilm producers, although the majority were weak biofilm producers $(n=83$; 70\%) (Figure 1).

The percentage of food isolates that were moderate biofilm producers was slightly higher than the percentage obtained for clinical isolates at $37^{\circ} \mathrm{C}$ (Figure 1).

At $4^{\circ} \mathrm{C}$, clinical isolates were weak $(n=70 ; 59 \%)$ or nonbiofilm producers $(n=48 ; 41 \%)$. Food isolates were nonformers $(n=143,24 \%)$, weak $(n=397 ; 65 \%)$ or moderate $(n=67 ; 11 \%)$ biofilm producers (Figure 2 ).

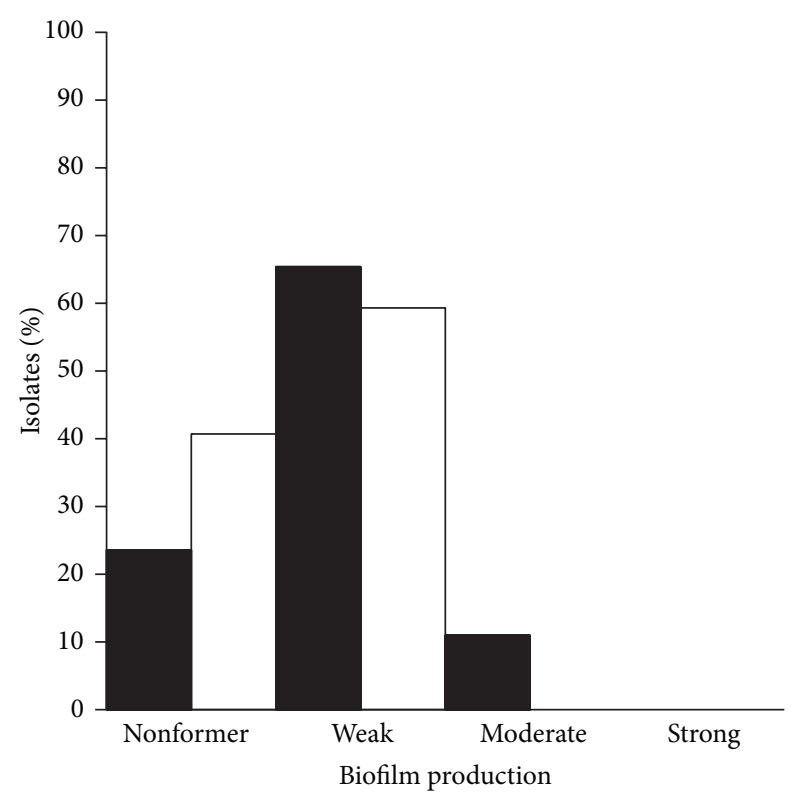

FIgURE 2: Biofilm production by clinical ( $\square$ ) and food ( $\mathbf{\square})$ isolates of L. monocytogenes at $4^{\circ} \mathrm{C}$ during 5 days.

Serogroups IIa and IIb (and IIc for clinical isolates) included the highest percentage of isolates showing the strongest activity to form biofilms at $37^{\circ} \mathrm{C}$ during $24 \mathrm{~h}$; the opposite was observed for serogroup IVb (Table 1). At $4^{\circ} \mathrm{C}$ during 5 days, as most of the isolates were classified as nonor weak-biofilm formers, no correlation between biofilm forming capacity and serogroup was observed (Table 1).

Five food isolates of L. monocytogenes were chosen in order to study the effect of two sublethal stress conditions (acidic and osmotic) in their ability to subsequently form biofilms at 37 and $4^{\circ} \mathrm{C}$. After exposure to the stress conditions, it was observed that isolate 1592/2 was sensitised by acidic exposure, since its biofilm formation ability at $37^{\circ} \mathrm{C}$ was reduced (Figure 3 ). However, at $4^{\circ} \mathrm{C}$, the exposure to the stress conditions neither conferred sensitivity nor resistance to all the studied isolates since no significant differences were demonstrated (Figure 4). 


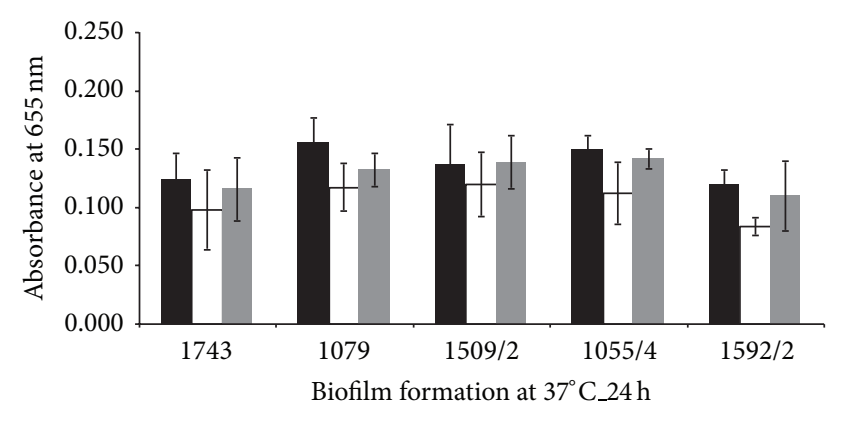

- Preexposure to BPW at pH 7.0 (control)
$\square$ Preexposure to acidic sublethal
Preexposure to osmotic sublethal

FIGURE 3: Values of absorbance at $655 \mathrm{~nm}$ obtained for five $L$. monocytogenes isolates after being exposed to acidic and osmotic sublethal stresses and tested for biofilm formation at $37^{\circ} \mathrm{C}$ during $24 \mathrm{~h}$.

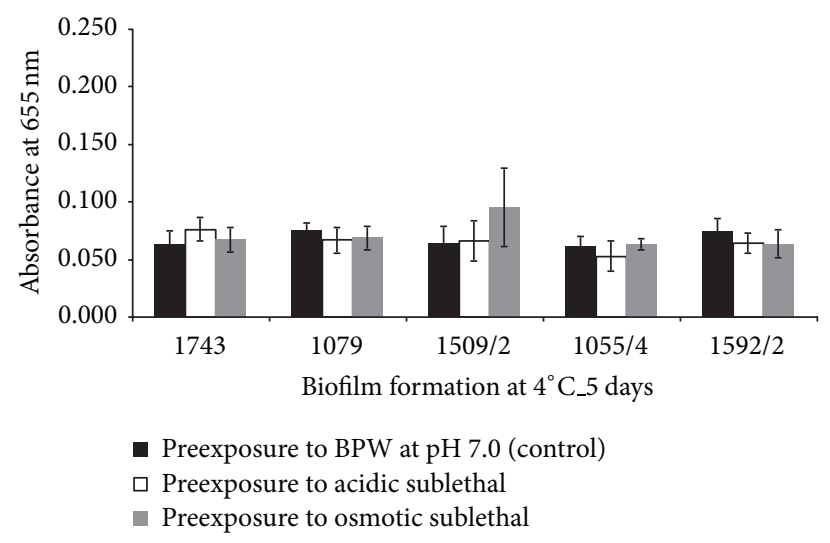

Figure 4: Values of absorbance at $655 \mathrm{~nm}$ obtained for five $L$. monocytogenes isolates after being exposed to acidic and osmotic sublethal stresses and tested for biofilm formation at $4^{\circ} \mathrm{C}$ during 5 days.

The influence of temperature on the ability of L. monocytogenes isolates to form biofilms has been reported by several authors [17, 24-26]. Chavant et al. [24] showed that L. monocytogenes $\mathrm{LO} 28$ colonized a polytetrafluoroethylene (PTFE) surface at $37^{\circ} \mathrm{C}$, but not at $8^{\circ} \mathrm{C}$. Di Bonaventura et al. [25] demonstrated that biofilm production on polystyrene surfaces by 44 different isolates of $L$. monocytogenes was significantly higher at $37^{\circ} \mathrm{C}$ than at $4^{\circ} \mathrm{C}$. Norwood and Gilmour [17], however, reported two L. monocytogenes isolates that adhered equally at $4^{\circ} \mathrm{C}$ and $30^{\circ} \mathrm{C}$. In the present study the temperature affected the capacity of the tested isolates to form biofilms. This capacity was shown to be dependent on the strain and on the origin of the isolate. It is important to underline the results obtained in this study in terms of strong biofilm formation by clinical isolates. Though there is a lack of literature referring to differences in biofilm production between food and clinical isolates, clinical isolates may be more adapted to temperatures close to body temperature, and this could be a possible reason for their moderate or strong biofilm production at $37^{\circ} \mathrm{C}$.
Serogroups IIa and IIb (and IIc for food isolates) included the highest percentage of isolates showing the strongest activity to form biofilms at $37^{\circ} \mathrm{C}$. Nilsson et al. [27] reported that among food and clinical isolates of L. monocytogenes $(n=95)$, serotype $1 / 2$ a (belonging to serogroup IIa) isolates produced significantly more biofilm than the other serotypes tested.

The behaviors of five food isolates of $L$. monocytogenes were investigated for their ability to produce biofilms, after exposure to acidic and osmotic sublethal stress conditions. It is reported that sublethal conditions frequently enhance the resistance of the microorganisms to subsequent stresses [28]. The cross-resistance of adapted cells to other stresses has important implications for the food industry, particularly since foods commonly encounter sublethal acidic treatments during processing [29]. Concerning strain 1592/2, after exposure to acidic sublethal stress conditions, its ability to form a biofilm at $37^{\circ} \mathrm{C}$ was reduced. Concerning the osmotic exposure at $37^{\circ} \mathrm{C}$ as well as the exposure to both sublethal conditions no differences in the capacity to form biofilm were observed at $4^{\circ} \mathrm{C}$. Adrião et al. [30] investigated the behavior of some L. monocytogenes isolates isolated from the environment of artisanal cheese-making dairies in response to acid and salt stress. It was demonstrated that for some of these isolates, salt or acid adaptation may enhance the survival/resistance of sessile cells exposed to hypochlorite disinfection. Also Longhi et al. [15] studied a protease treatment and found that the treatment of L. monocytogenes with sublethal concentrations of an extracellular metalloprotease reduced the ability to form biofilms. Nilsson et al. [27] suggested that environmental conditions determine the level of biofilm production by L. monocytogenes isolates, independent of the rate of planktonic growth.

\section{Conclusions}

In the present work, significant differences between clinical and food isolates were observed concerning their ability to form biofilms. This ability was also influenced by the temperature used, being the biofilm formation increased at $37^{\circ} \mathrm{C}$. Considering the sublethal acidic stress, biofilm formation ability was reduced only for one isolate. For sublethal osmotic stress, no changes on biofilm formation ability were observed. To explain the differences in biofilm production between food and clinical L. monocytogenes isolates, as well as the influence of environmental factors such as temperature, further investigations would be required, such as testing biofilm production on different surfaces relevant to food and clinical environments and the resistance of L. monocytogenes isolates, both in suspension and as biofilms, to sanitizing agents used in both clinical and food processing environments. Also further studies of the effect of more sublethal stresses on the behaviour of clinical and food isolates would be important.

\section{Conflict of Interests}

All the authors certify that no actual or potential conflict of interests in relation to this paper exists. 


\section{Acknowledgments}

This work was supported by National Funds from Fundação para a Ciência e a Tecnologia (FCT) through projects PEstOE/EQB/LA0016/2011 and PTDC/AGR-ALI/64662/ 2006. Financial support for authors Joana Barbosa, Rui Magalhães, Vânia Ferreira, and Joana Silva was provided by Fundação para a Ciência e a Tecnologia through, respectively, $\mathrm{PhD}$ fellowship SFRH/BD/48894/2008, PhD fellowship SFRH/BD/ 71704/2010, Postdoctoral fellowship SFRH/BPD/72617/2010, and Postdoctoral fellowship SFRH/BPD/35392/2007. Editing of this paper by Dr. P. A. Gibbs is gratefully acknowledged.

\section{References}

[1] G. N. Almeida, P. A. Gibbs, T. A. Hogg, and P. C. Teixeira, "Listeriosis in Portugal: an existing but under reported infection," BMC Infectious Diseases, vol. 6, article 153, 2006.

[2] EFSA, "The European Union summary report on trends and sources of zoonoses, zoonotic agents and food-borne outbreaks in 2009," EFSA Journal, vol. 9, no. 3, article 2090, p. 378, 2011.

[3] T. Møretrø and S. Langsrud, "Listeria monocytogenes: biofilm formation and persistence in food-processing environments," Biofilms, vol. 1, pp. 107-121, 2004.

[4] B. Carpentier and O. Cerf, "Review-persistence of Listeria monocytogenes in food industry equipment and premises," International Journal of Food Microbiology, vol. 145, no. 1, pp. 1-8, 2011.

[5] V. Ferreira, J. Barbosa, M. Stasiewicz et al., "Diverse genoand phenotypes of persistent Listeria monocytogenes isolates from fermented meat sausage production facilities in Portugal," Applied and Environmental Microbiology, vol. 77, no. 8, pp. 27012715, 2011.

[6] A. Rieu, R. Briandet, O. Habimana, D. Garmyn, J. Guzzo, and P. Piveteau, "Listeria monocytogenes EGD-e biofilms: no mushrooms but a network of knitted chains," Applied and Environmental Microbiology, vol. 74, no. 14, pp. 4491-4497, 2008.

[7] M. L. Kalmokoff, J. W. Austin, X.-D. Wan, G. Sanders, S. Banerjee, and J. M. Farber, "Adsorption, attachment and biofilm formation among isolates of Listeria monocytogenes using model conditions," Journal of Applied Microbiology, vol. 91, no. 4, pp. 725-734, 2001.

[8] M. K. Borucki, J. D. Peppin, D. White, F. Loge, and D. R. Call, "Variation in biofilm formation among strains of Listeria monocytogenes," Applied and Environmental Microbiology, vol. 69, no. 12, pp. 7336-7342, 2003.

[9] P. Chavant, B. Gaillard-Martinie, and M. Hébraud, "Antimicrobial effects of sanitizers against planktonic and sessile Listeria monocytogenes cells according to the growth phase," FEMS Microbiology Letters, vol. 236, no. 2, pp. 241-248, 2004.

[10] J. M. Lundén, T. J. Autio, and H. J. Korkeala, “Transfer of persistent Listeria monocytogenes contamination between foodprocessing plants associated with a dicing machine," Journal of Food Protection, vol. 65, no. 7, pp. 1129-1133, 2002.

[11] M. S. Chae and H. Schraft, "Comparative evaluation of adhesion and biofilm formation of different Listeria monocytogenes strains," International Journal of Food Microbiology, vol. 62, no. 1-2, pp. 103-111, 2000.

[12] J. Harvey, K. P. Keenan, and A. Gilmour, "Assessing biofilm formation by Listeria monocytogenes strains," Food Microbiology, vol. 24, no. 4, pp. 380-392, 2007.
[13] I. C. Blackman and J. F. Frank, "Growth of Listeria monocytogenes as a biofilm on various food-processing surfaces," Journal of Food Protection, vol. 59, no. 8, pp. 827-831, 1996.

[14] S. Stepanović, I. Ćirković, L. Ranin, and M. Svabić-Vlahović, "Biofilm formation by Salmonella spp. and Listeria monocytogenes on plastic surface," Letters in Applied Microbiology, vol. 38, pp. 428-432, 2004.

[15] C. Longhi, G. L. Scoarughi, F. Poggiali et al., "Protease treatment affects both invasion ability and biofilm formation in Listeria monocytogenes," Microbial Pathogenesis, vol. 45, no. 1, pp. 4552, 2008.

[16] R. Briandet, V. Leriche, B. Carpentier, and M. Bellon-Fontaine, "Effects of the growth procedure on the surface hydrophobicity of Listeria monocytogenes cells and their adhesion to stainless steel," Journal of Food Protection, vol. 62, no. 9, pp. 994-998, 1999.

[17] D. E. Norwood and A. Gilmour, "The differential adherence capabilities of two Listeria monocytogenes strains in monoculture and multispecies biofilms as a function of temperature," Letters in Applied Microbiology, vol. 33, no. 4, pp. 320-324, 2001.

[18] D. Djordjevic, M. Wiedmann, and L. A. McLandsborough, "Microtiter plate assay for assessment of Listeria monocytogenes biofilm formation," Applied and Environmental Microbiology, vol. 68, no. 6, pp. 2950-2958, 2002.

[19] J. P. Folsom, G. R. Siragusa, and J. F. Frank, "Formation of biofilm at different nutrient by various genotypes of Listeria monocytogenes," Journal of Food Protection, vol. 69, no. 4, pp. 826-834, 2006.

[20] M. Begley, C. Kerr, and C. Hill, "Exposure to bile influences biofilm formation by Listeria monocytogenes," Gut Pathogens, vol. 1, pp. 1-4, 2009.

[21] N. Cerca, G. B. Pier, M. Vilanova, R. Oliveira, and J. Azeredo, "Influence of batch or fed-batch growth on Staphylococcus epidermidis biofilm formation," Letters in Applied Microbiology, vol. 39, no. 5, pp. 420-424, 2004.

[22] A. A. Miles and S. S. Misra, "The estimation of the bactericidal power of the blood," The Journal of Hygiene, vol. 38, pp. 732-749, 1938.

[23] J. Barbosa, S. Borges, R. Magalhães et al., "Behaviour of Listeria monocytogenes isolates through gastro-intestinal tract passage simulation, before and after two sub-lethal stresses," Food Microbiology, vol. 30, no. 1, pp. 24-28, 2012.

[24] P. Chavant, B. Martinie, T. Meylheuc, M. Bellon-Fontaine, and M. Hebraud, "Listeria monocytogenes LO28: surface physicochemical properties and ability to form biofilms at different temperatures and growth phases," Applied and Environmental Microbiology, vol. 68, no. 2, pp. 728-737, 2002.

[25] G. Di Bonaventura, R. Piccolomini, D. Paludi et al., "Influence of temperature on biofilm formation by Listeria monocytogenes on various food-contact surfaces: relationship with motility and cell surface hydrophobicity," Journal of Applied Microbiology, vol. 104, no. 6, pp. 1552-1561, 2008.

[26] L. M. Smoot and M. D. Pierson, "Effect of environmental stress on the ability of Listeria monocytogenes Scott A to attach to food contact surfaces," Journal of Food Protection, vol. 61, no. 10, pp. 1293-1298, 1998.

[27] R. E. Nilsson, T. Ross, and J. P. Bowman, "Variability in biofilm production by Listeria monocytogenes correlated to strain origin and growth conditions," International Journal of Food Microbiology, vol. 150, no. 1, pp. 14-24, 2011.

[28] M. L. Faleiro, P. W. Andrew, and D. Power, "Stress response of Listeria monocytogenes isolated from cheese and other foods," 
International Journal of Food Microbiology, vol. 84, no. 2, pp. 207-216, 2003.

[29] M. Gandhi and M. L. Chikindas, "Listeria: a foodborne pathogen that knows how to survive," International Journal of Food Microbiology, vol. 113, no. 1, pp. 1-15, 2007.

[30] A. Adrião, M. Vieira, I. Fernandes et al., "Marked intra-strain variation in response of Listeria monocytogenes dairy isolates to acid or salt stress and the effect of acid or salt adaptation on adherence to abiotic surfaces," International Journal of Food Microbiology, vol. 123, no. 1-2, pp. 142-150, 2008. 

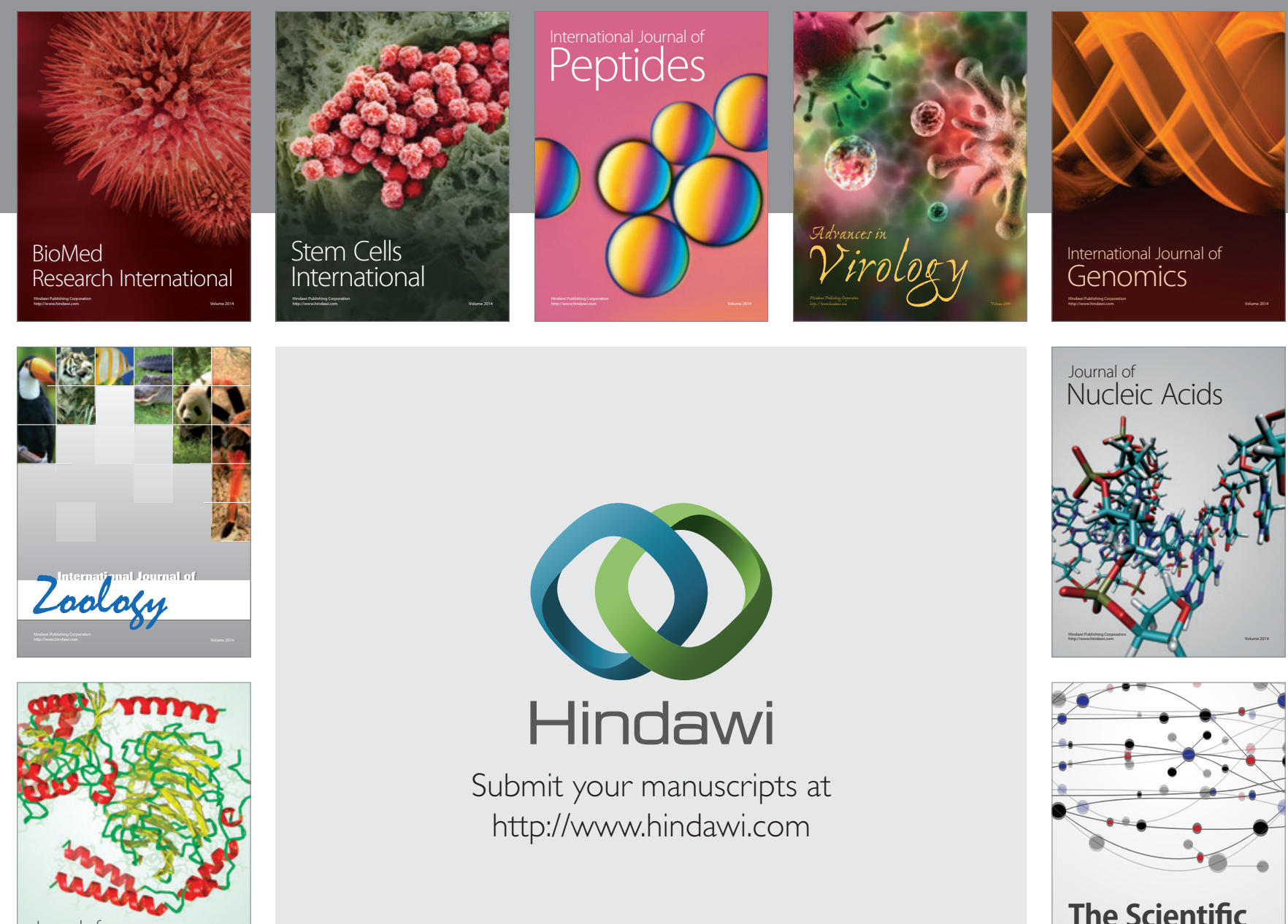

Submit your manuscripts at

http://www.hindawi.com

Journal of
Signal Transduction
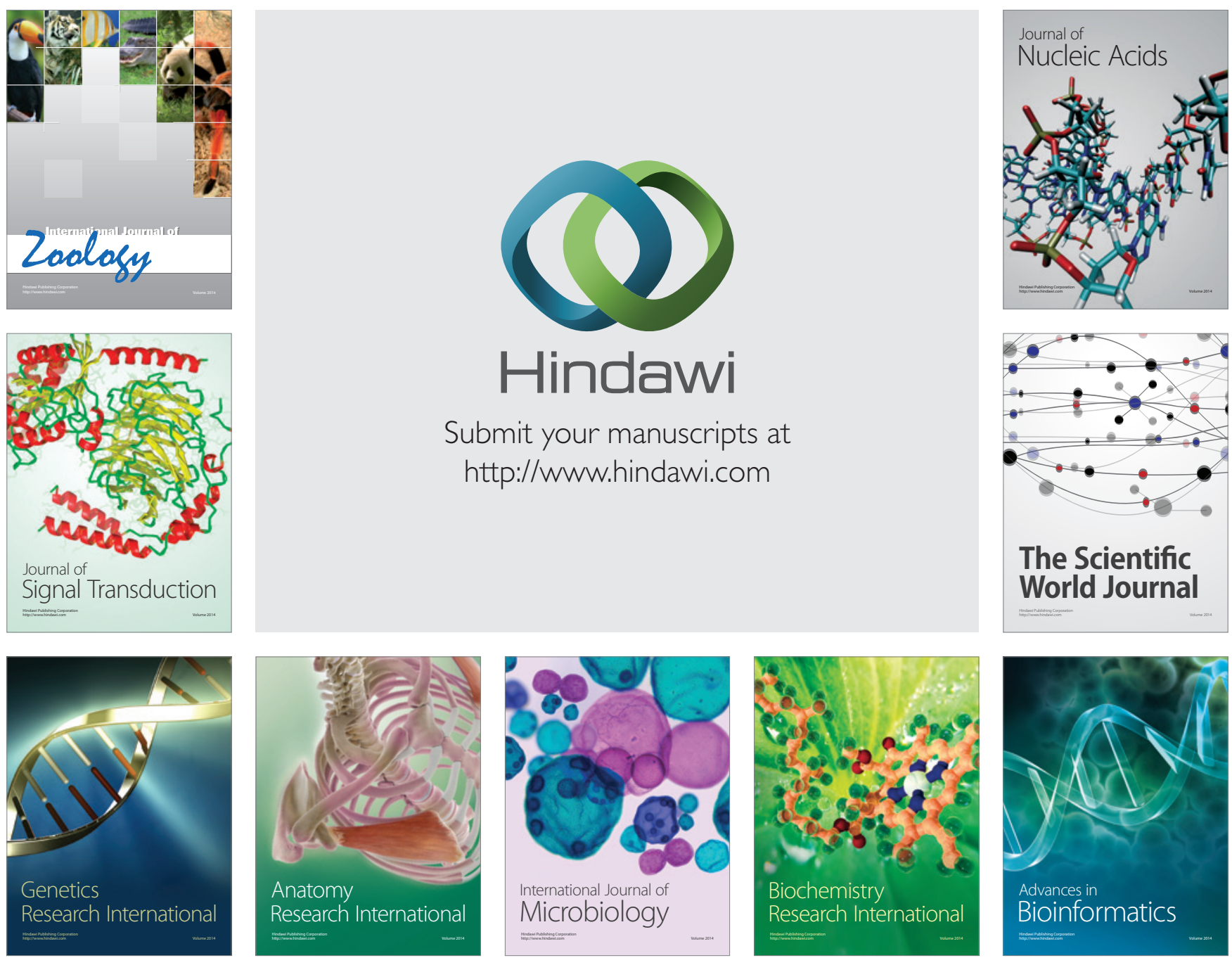

The Scientific World Journal
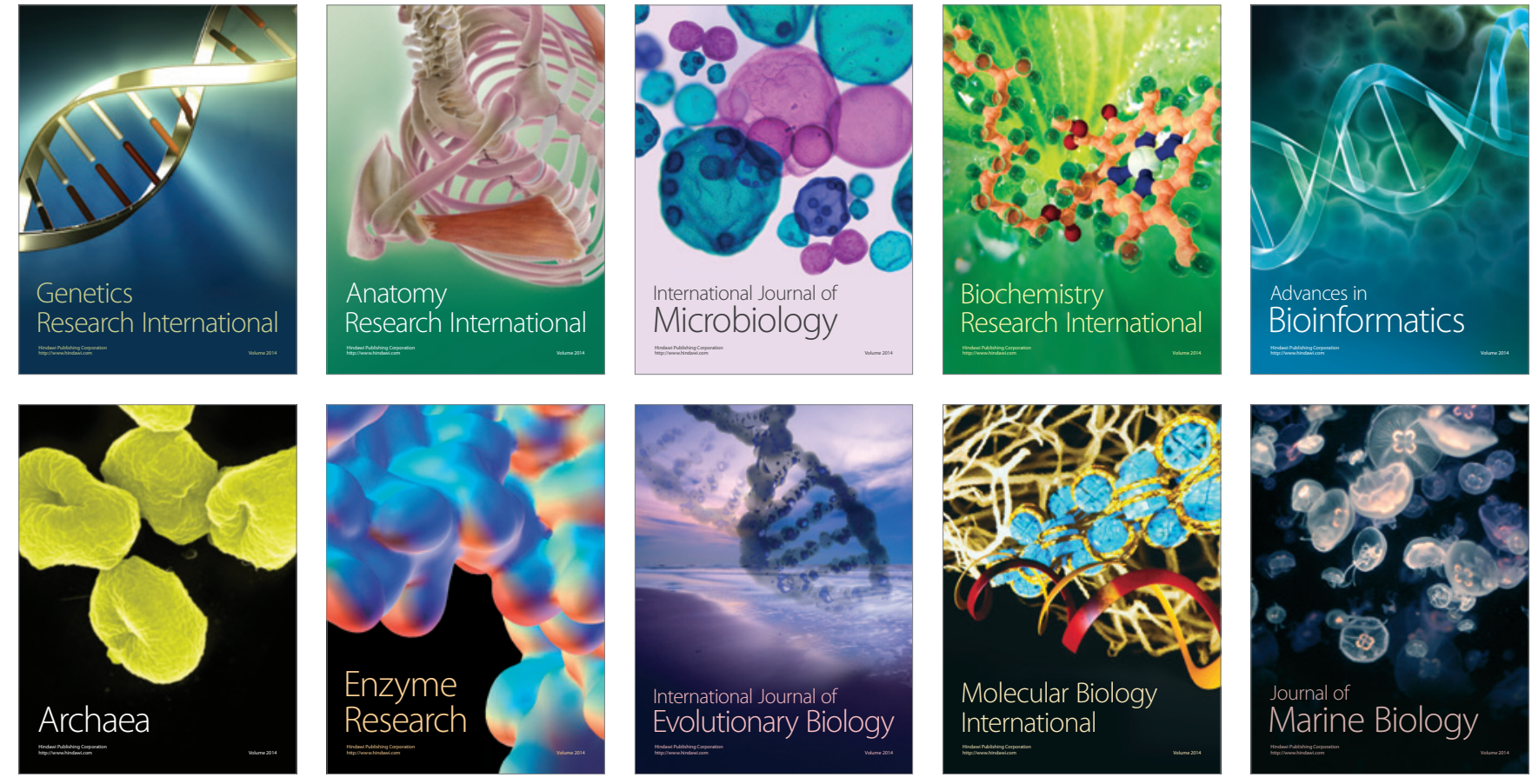